\title{
MODELAGEM MULTINÍVEL DOS CONCEITOS DA CLASSIFICAÇÃO INTERNACIONAL PARA A PRÁTICA DE ENFERMAGEM ASSOCIADA AO ESTADO FUNCIONAL DO IDOSO
}

\author{
Multilevel Modeling of Concepts of International Classification for Nursing \\ Practice Associated with Functional Status of Elderly \\ Joyce Rocha de Matos Nogueira'; Luciana Tricai Cavalini²
}

\begin{abstract}
Resumo Os termos do Catálogo Nursing Outcomes Indicators da Classificação Internacional para a Prática de Enfermagem foram mapeados para arquétipos openEHR disponíveis no Clinical Knowledge Manager. O conceito de Estado Funcional permitiu o uso direto do arquétipo Barthel Index para parte de seus termos, demonstrando viabilidade de mapeamento entre terminologias de enfermagem e os modelos de dados das especificações openEHR.
\end{abstract}

Palavras-chave: Sistemas de Informação, Informática em Enfermagem, Terminologia

\begin{abstract}
The Catalog Nursing Outcomes Indicators' terms of the International Classification for Nursing Practice were mapped to openEHR archetypes available in Clinical Knowledge Manager. The concept of Functional Status allowed the direct use of the archetype "Barthel Index" for part of its terms, demonstrating the feasibility of mapping between nursing terminologies and data models of openEHR specifications.
\end{abstract}

Keywords: Information Systems, Nursing Informatics, Terminology

Introdução: A aplicação de recursos informatizados se traduz em vantagens e melhorias para o desempenho da prática de enfermagem, promovendo a padronização dos parâmetros de atendimento, o que facilita a coleta, processamento e recuperação de dados, reduzindo custos e tempo no sistema de saúde. Assim, padrões de informática em saúde, tais como as terminologias, têm o potencial de transformar a assistência de enfermagem, tornando-a mais organizada e adequada às necessidades de cada ambiente de saúde. No entanto, sistemas de informação em saúde com base em arquitetura de software convencional não são semanticamente interoperáveis e têm altos custos de manutenção. Tais obstáculos podem ser removidos com a adoção da abordagem denominada modelagem multinível, sendo que uma de suas implementações são as especificações openEHR.

Objetivo: Apresentar um caso de uso da conversão de uma terminologia de enfermagem para o modelo openEHR.

Método: Os termos do Catálogo Nursing Outcomes Indicators da Classificação Internacional para a Prática de Enfermagem foram mapeados para arquétipos openEHR disponíveis no Clinical Knowledge Manager, o repositório global de arquétipos openEHR. Quatro conceitos do Catálogo foram cobertos por arquétipos openEHR: Estado Funcional, Continência Urinária,

1. Psicóloga da Secretaria Municipal de Educação de Três Rios - Especialização em Gestão Hospitalar; 2. Professora Adjunta do Departamento de Tecnologias da Informação e Educação em Saúde - Faculdade de Ciências Médicas - Universidade do Estado do Rio de Janeiro - Doutorado em Saúde Pública. 
Dor e Úlceras de Pressão, e cinco não o foram: Fadiga, Dispneia, Náuseas, Quedas e Condições de Alta. Os conceitos de Continência Urinária, Dor e Úlceras de Pressão não puderam ser completamente mapeados, pois seus modelos de dados foram conceitual e estruturalmente diferentes dos arquétipos openEHR mais próximos. O conceito de Estado Funcional permitiu o uso direto do arquétipo "Barthel Index" para uma parte de seus termos, mas será requerido o uso de um template. A partir disso, procedeu-se à modelagem dos conceitos do Estado Funcional do Catálogo Nursing Outcomes Indicators pela descrição dos termos que compõem este subconjunto da terminologia em questão. A seguir, foi feita a análise da modelagem do conceito de Estado Funcional no arquétipo "Barthel Index", a partir de uma descrição minuciosa de toda a sua estrutura, incluindo cabeçalho, definição e ontologia. O mapeamento dos termos do Catálogo Nursing Outcomes Indicators para os ELEMENT do arquétipo "Barthel Index" evidenciou a necessidade de se elaborar um arquétipo específico para os termos do conceito de Atividades Instrumentais da Vida Diária do Ca- tálogo, pois estes não encontraram correspondência com os ELEMENTs do arquétipo obtido no CKM.

Discussão: O mapeamento resultante apresentou uma complexidade significativa e a implementação em sistemas de informação em saúde reais dos modelos de dados resultantes seria de difícil operacionalização. O mapeamento semântico utilizando o modelo openEHR demonstrou que este foi suficiente para representar a semântica dos conceitos do Catálogo Nursing Outcomes Indicators referentes ao Estado Funcional do Idoso, embora problemas quanto a diferenças na granularidade de documentação entre o banco de dados utilizado e os arquétipos existentes tenham sido encontrados durante o processo.

Conclusões: $O$ presente estudo demonstrou a viabilidade de mapeamento entre terminologias de enfermagem e os modelos de dados das especificações openEHR, o que enfatiza a importância da adoção da modelagem multinível para a aquisição de interoperabilidade semântica entre sistemas de informação em saúde. 